\title{
Adherence to prescribed drug therapy among adult patients of General Out-Patient Department of a Tertiary Hospital in Nigeria
}

\author{
*Salaudeen A.G. ${ }^{1}$, Akande T.M. ${ }^{1}$, Ologe M. ${ }^{2}$, Odeigha L.O. ${ }^{3}$, Medubi G.F. ${ }^{4}$
}

\begin{abstract}
Objective: The widespread problems of adherence to medication denied substantial number of patients the maximum benefits of medical treatment, resulting in poor health outcomes, lower quality of life and increased health care costs. The objective of this study was to determine the extent of drug adherence among patients seen in a tertiary hospital in Nigeria.
\end{abstract}

Methods: The study was a descriptive cross-sectional survey carried out among 381 patients attending the General Out-Patient Department (GOPD) of a Teaching Hospital in Nigeria. Interviewer administered questionnaire was used as the research tool and case notes of the patients were used to obtain information on drug adherence.

Results: About half of the patients 194 (50.9\%) adhered fully with doctor's prescription on the use of drugs for diseases they presented to the hospital. More than three quarters $(78.0 \%)$ of patients aged 56 years and above adhered fully with prescription compared with $11.1 \%$ in the age group $15-25$ years. The older patients had better adherence to medication than the younger patients with a statistically significant difference $(\mathrm{p}=0.001)$. Many of the patients with no formal education $(69.0 \%)$ adhered fully with prescription compared with $28.6 \%$ with post secondary education $\mathrm{p}=0.001$.

Conclusion: Health education intervention and active role of health care providers in patients'-provider communication towards addressing the determinants of non-adherence will play a major role in improving adherence to medication

Key words: Drug, adherence, Teaching, Hospital, Nigeria

\footnotetext{
*Correspondence author

Salaudeen A.G.

http://orcid.org/0000-0001-8215-1782

E-mail: adekunlesalaudeen@yahoo.com
}

${ }^{1}$ Department of Epidemiology \& Community Health, College of Health Sciences, University of Ilorin, Ilorin, Nigeria

${ }^{2}$ Department of Pharmacology and Therapeutics, College of Health Sciences, University of Ilorin, Ilorin, Nigeria

${ }^{3}$ Department of Family Medicine, University of Ilorin Teaching Hospital, Ilorin, Nigeria

${ }^{4}$ Department of Pharmacy, University of Ilorin Teaching Hospital, Ilorin, Nigeria 


\title{
Adhésion aux médicaments prescrits chez les patients adultes au sein d'un centre hospitalier universitaire au Nigéria (consultations externes).
}

\author{
*Salaudeen A.G. ${ }^{1}$, Akande T.M. ${ }^{1}$, Ologe M. ${ }^{2}$, Odeigha L.O. ${ }^{3}$, Medubi G.F. ${ }^{4}$ \\ Résumé : \\ Objectif: Les problèmes liés au refus d'adhésion aux médicaments, répandus chez un grand nombre de \\ patients, réduisent le bénéfice maximum d'un traitement médical. Il en résulte : de piètres résultats en \\ matière de santé, une qualité de vie inférieure et une augmentation des dépenses de santé. L'objectif de \\ cette étude est d'évaluer le degré d'adhésion aux médicaments chez les patients observés dans un centre \\ hospitalier universitaire au Nigéria.
}

Méthodes: Cette étude fut l'objet d'une enquête transversale menée sur 381 patients ayant fréquenté le service des consultations externes d'un CHU au Nigéria. Au niveau des moyens de recherche, l'enquêteur a remis des questionnaires aux patients et s'est intéressé à leurs dossiers médicaux pour obtenir des informations sur la propension à respecter les consignes de traitement.

Résultats: Près de la moitié des patients, 194 au total, (soit 50,9\%) ont parfaitement respecté la prescription de médicaments du médecin pour traiter les maladies diagnostiquées à l'hôpital. Plus de trois quarts $(78 \%)$ des patients âgés de 56 ans et + ont adhéré pleinement à la prescription. A contrario, la fourchette des 15-25 ans ne l'a respectée qu'à $11,1 \%$. Les patients âgés respectent plus les consignes de traitement que les jeunes patients, ce que démontre une statistique significative $(p=0,001)$. Un grand nombre de patients sans éducation scolaire de base (69\%) ont parfaitement respecté la prescription médicale, soit plus que ceux ayant bénéficié d'une éducation dans le secondaire ou dans le supérieur. $(28,6 \%) \mathrm{p}=0,001$.

Conclusion: La mise en place d'une éducation sanitaire et le rôle actif des professionnels de la santé, dans la communication des facteurs de non-adhésion, joueront un rôle prépondérant pour obtenir un meilleur respect des prescriptions médicales.

Mots clés: Médicaments, adhésion, enseignement, hôpital, Nigéria.

\author{
*Correspondence author \\ Salaudeen A.G. \\ http://orcid.org/0000-0001-8215-1782 \\ E-mail: adekunlesalaudeen@yahoo.com
}

${ }^{1}$ Department of Epidemiology \& Community Health, College of Health Sciences, University of Ilorin, Ilorin, Nigeria

${ }^{2}$ Department of Pharmacology and Therapeutics, College of Health Sciences, University of Ilorin, Ilorin, Nigeria ${ }^{3}$ Department of Family Medicine, University of Ilorin Teaching Hospital, Ilorin, Nigeria

${ }^{4}$ Department of Pharmacy, University of Ilorin Teaching Hospital, Ilorin, Nigeria 


\section{INTRODUCTION}

Correct diagnosis and effective medical treatment are essential to improve quality of life and patient survival. The goal of any prescribed medical therapy is to achieve certain desired outcomes in the patient concerned; these outcomes however, may not be achieved if there is failure on the part of patient to follow the recommendations of healthcare provider. Therapeutic adherence, as defined by the WHO, is 'the extent to which a person's behaviourtaking medication, following a diet and/or executing lifestyle changes - corresponds with agreed recommendations from a healthcare provider'(1). Non-adherence to pharmacological therapy, especially in patients with chronic health conditions, is a growing concern worldwide which constitutes a major barrier to safe, costeffective and effective use of drugs (1).

The factors driving patients' adherence to medication are multifactorial, but can be grouped under five main domains (2) including socioeconomic factors such as health literacy, medication cost, availability of health insurance, cultural beliefs about the illness and treatment. Second, factors related to the healthcare system such as provider- patient relationship, provider communication skills, presence of community care and short waiting time. Third, factors related to conditions such as absence of symptoms, chronic conditions, depression and psychotic disorders. Fourth, therapy-related factors such as duration of therapy, frequency of changes in medication, absence of side effects, number of daily doses and absence of concurrent medication and finally, patient-related factors such as motivation, good knowledge about medication and perceived benefit of treatment (2).

In 2009, treatment cost for chronic condition contributed to an estimated cost of \$290 Billion annually in the United States (3). In 2012, increase in patient medication cost share was found to be associated with low adherence to medication (4). The United States is among the countries with the highest prices of prescription drugs mainly attributed to the government's lack of negotiating lower prices with monopolies in the pharmaceutical industry especially with brand name drugs (5). In order to manage medication costs, many US patients on long term therapies fail to fill their prescription, skip or reduce doses. According to a Kaiser Family Foundation survey in 2015, about three quarters $(73 \%)$ of the public think drug prices are unreasonable and blame pharmaceutical companies for setting prices so high (6). In the same report, half of the public reported that they are taking prescription drugs and a "quarter $(25 \%)$ of those currently taking prescription medicine report they or a family member have not filled a prescription in the past 12 months due to cost, and 18 percent report cutting pills in half or skipping doses" (6). In a 2009 comparison to Canada, only $8 \%$ of adults reported to have skipped their doses or not filling their prescriptions due to the cost of their prescribed medications (7).

Major barriers to compliance are thought to include the complexity of modern medication regimens, poor "health literacy" and not understanding treatment benefits, occurrence of undiscussed side effects, poor treatment satisfaction, cost of prescription medicine, and poor communication or lack of trust between a patient and his or her health-care provider (8-11). Efforts to improve compliance have been aimed at simplifying medication packaging, providing effective medication reminders, improving patient education, and limiting the number of medications prescribed simultaneously. Studies show a great variation in terms of characteristics and effects of interventions to improve medicine adherence (12). It is still unclear how adherence can consistently be improved in order to promote clinically important effects (12).

Further studies have also shown that adherence rates were higher with regimens containing three or fewer doses a day (13). A meta-analysis showed that the average adherence rate to anti hypertension drug was significantly higher for single daily dosage than for multiple daily dosage. However, the longer the therapy lasted, the lower the adherence rate (13).

In developing countries especially Nigeria where resources are limited and data on adherence to medical treatment is scarce there is need for research that will identify how patients comply with medical treatment. This study explored the extent of drug adherence and related factors among patients seen in a tertiary hospital in Nigeria.

\section{MATERIALS AND METHODS}

The study was carried out in the General Out-Patient Department (GOPD) of the University of Ilorin Teaching Hospital in Nigeria (UITH). It is a descriptive cross sectional study done among patient on follow up visit to the clinic. The inclusion criteria were diagnosis of disease must have been made, patients must have been on treatment and came for follow up visit. Patients that were less than 15 years of age were 
not used in this study. Patients were randomly selected over a period of 4 weeks.

Pretested interviewer administered questionnaire was used as the research tool and case notes of the patients were used to obtain some information on regular clinic visit to elicit adherence to medication. Research assistants were trained to administer questionnaire on drug adherence. Pre and post test assessment was conducted for the research assistants to determine their level of understanding of the research tool. Verbal consent was obtained from the patients. Data obtained were manually sorted and entered into personal computer. Data collected were analysed using EPI-Info software package. Data collected presented in prose and frequency tables. Descriptive statistics such as Mean was used to analyse the average age of Patients receiving treatment. Frequency distribution and other relevant summary statistics generated. Appropriate tests of significance (chi-square test) was used to test statistic. Statistical significance was set at $p$-value $<0.05$. For this study, full adherence means patients who took the drugs as prescribed in the right dosage, number of times in a day and for the prescribed number of days. This was obtained by comparing the instructions from doctors and adherence of the patients. The case notes and information obtained from the patients through the questionnaire were used to assess the level of adherence of each patient.

Ethical clearance to conduct the study was obtained from the ethical review committee of University of Ilorin Teaching Hospital before the commencement of the study. Respondents were informed about the objectives of the study and that the data collected will be treated with confidentiality.

\section{RESULTS}

A total of 381 patients were interviewed. About three-quarters (74.1\%) of the respondents were males and $70.1 \%$ were married. About three-quarters $(73.0 \%)$ of the respondent had at least primary school education (table 1). Among the 259 respondents who indicated where they had received treatment before presenting to the hospital, private clinic was the most common place $(46.2 \%)$ and about a quarter received treatment in public health facilities (Table 2). Drug treatment was the main form of treatment received before attending UITH and accounted for $93.2 \%$ of treatment received followed by traditional medications $(7.6 \%)$.

Majority of the patients $243(63.8 \%)$ were diagnosed to have non communicable diseases. Hypertension, peptic ulcer disease and arthritis constituted majority of the disease conditions presented to the hospital by the patients. The common communicable diseases $(36.2 \%)$ reported were tuberculosis $(4.2 \%)$ and pneumonia (3.6\%). About two-thirds $(66.8 \%)$ of the patients obtained their prescribed drugs from the University Teaching Hospital Pharmacy, $(28.8 \%)$ got their medications from pharmacy stores outside the hospital while only a few of them $(4.5 \%)$ patronized patent medicine stores for their drugs.

There were variations in level of adherence with medication among the respondents. The mean number of days drugs were prescribed for the respondents was $13.3 \pm$ 2.7, and mean number of days drugs were used was $7.1 \pm 1.3$. The mean number of times per day drug should be taken was $1.8 \pm 2.1$; however the number of times drug was used in a day was $1.1 \pm$ 3.7. The mean expected number of tablets to be swallowed in a day was $9.0 \pm 3.2$ but the mean number of tablets used by the respondents was $5.0 \pm 1.1$.

Only about half of the patients 194 (50.9\%) adhered fully with doctor's prescription on the use of drugs for diseases they presented to the hospital. The reasons given for nonadherence to drug prescription by the patients were; inability to buy prescribed drugs (17.5\%), inability to buy enough drugs $(22 . \% \%)$, forgot to take drug as prescribed (15.0\%), drugs prescribed were too many $(12.5 \%)$, felt well and stopped taking drugs $(20.0 \%)$ and side effects of the drugs $(12.5 \%)$

More than three quarters $(78.0 \%)$ of patients aged 56 years and above adhered fully with prescription compared with $11.1 \%$ in the age group 15-25 years. This showed a strong association between adherence rate and increasing age of patients $(p<0.01)$. A relatively high proportion of the patients with no formal education (69.0\%) also adhered fully with prescription compared with only $28.6 \%$ of the patients with post secondary education which was also statistically significant, $\mathrm{p}<0.01$. (0.0006)

Of the patients interviewed, 91.1\% received information on the prescribed drugs from the doctors and almost all $(97.0 \%)$ were given information on the prescribed drugs by the pharmacists or patient medicine sellers. Of the 347 patients that received information on prescribed drugs from doctors, $91.8 \%$ of them were given information on the number of times in a day to use the drugs, all were given information 
on number of the days to use the drugs and $90.5 \%$ were informed on the time to use the prescribed drugs. Other instructions given by doctors were to use the prescribed drugs after meals, use before meals and possible side effects of the drugs. Similarly, pharmacists and patent medicine sellers provided information on prescribed drugs as $96.8 \%$ of the patients interviewed were told the number of days to use the drugs, $97.0 \%$ were informed on number of times in a day drug should be taken and $90.5 \%$ received information on when the drug should be taken. Other information provided by the pharmacists was similar to the instructions doctors gave the patients.

\section{DISCUSSION}

This study revealed that more than twothirds $(68.0 \%)$ of the respondents had visited other clinics or hospitals for care before presenting at the University of Ilorin Teaching Hospital (UITH). This is because there are other clinics and private hospitals in the city where people can access health care services and many visit the tertiary hospital for specialist care. About half $(46.3 \%)$ of the patients had received treatment in private hospitals before presenting at UITH. This shows that greater proportions of patients are seen in the private health facilities in the state and a considerable proportion of patients that eventually need to get treatment in the Teaching Hospital were referred after initial visit to the private health facility.

Majority $(63.8 \%)$ of the patients are diagnosed to have non-communicable diseases. This shows that the prevalence of noncommunicable diseases is on the increase in our society and that tertiary hospitals see more patients affected by non-communicable diseases. Also, it could be because the General Out-patient Department (GOPD) of the teaching hospital provides primary and secondary health care services, and as such cases that could not be properly managed at primary health care centre and private clinics visit the GOPD thereby increasing the prevalence. Drug therapy accounted for $93.1 \%$ of treatment received by patients before attending UITH. This showed that drug therapy is the major form of treatment received in most health facilities. This further highlights the importance of drug adherence in treatment of diseases for good outcome of management as most patients were prescribed drugs during hospital visits.

The mean number of days drugs were prescribed for the patients was $13.3 \pm 2.7$, but mean number of days drugs were used by the patients was $7.1 \pm 1.3$. Adherence rate in terms of number of days drug taken was $53.4 \%$ in this study. Adherence to antihypertensive therapy in a study conducted in Pakistan was 77\% (14), which is significantly higher than findings from this study. In Malaysia adherence rate of $44.2 \%$ was observed (15). This finding though similar to observation in this study is lower. The variation observed could be due to measurement of adherence which was based on different criteria in the 3 studies and the study population. While this survey used all types of patients who visited the out-patient department of the hospital for follow-up, the study in Pakistan and Malaysia were only among hypertensive patients. The low adherence in this study could be due to long duration of taken drugs as many of them visit hospital for follow-up treatment. It has been established that the longer the duration of treatment the lower the adherence rate (1).

Adherence rate of $61.1 \%$ in number of times drugs was used in a day was revealed by this survey. This means that about $39 \%$ of times in a day 'on therapy' were not covered by medication. The frequency of use of drugs may affect patient adherence as patients with single daily dose tend to comply with medication as compared to multi daily doses. It is important for scientists and drug manufacturers to consider production of drugs with fewer frequency of administration (1).

The mean expected tablets to be swallowed in a day were $9.0 \pm 3.2$ but $5.0 \pm 1.1$ tablets were the mean number of tablet or capsules swallowed. Only $55.6 \%$ of number of tablets 'on therapy' was covered during the period of medication. This corroborates the findings from study on adherence in cardiovascular diseases where $59.0 \%$ of patients swallowed the expected number of tablets (16). The adherence to medication decreases with increasing number of tablets to be swallowed because the odour of the drug, work condition of the patient, lack of support from family and relation, forgetfulness and side effects of the drugs affect adherence to medication (2).

On the overall, $50.9 \%$ of the patients adhered fully with doctors' prescription. The challenges identified by patients militating against full adherence among others were high cost of prescribed drugs due to chronic nature of illness, forgetfulness and side effect of the drugs (1-3). In this study, there was observed increase in adherence with medication among the older age group (78.0\%). This could be that older age groups have better understanding of the disease, not willing to take chances of treatment failure or 
risk of developing complications from the disease. It is surprising that more patients with no formal education $(69.0 \%)$ complied with medication significantly compared to those that have post-secondary education $(28.6 \%)$ in this survey $(p<0.0001)$. More educated patients claimed 'busy schedules', 'tired of using drugs every day' and 'forgetfulness' as reasons for nonadherence with medications. However, these claims could not be affirmed as efforts to get similar studies for comparison could not be accessed at present. There was no statistically significant difference in gender variation in adherence to medication in this study.

Majority of the patients studied (97.0\%) received information on prescription from the health workers on the prescribed drugs. This showed that there was some form of communication between patients and health workers. This is expected because the hospital is a tertiary health care centre where ethical and specialized care is given due consideration. There is need to focus on individual patient characteristics and challenges to address the problem of adherence to medication.

There is no simple solution to the problem of adherence with prescribed medication, especially in the area of behavioural change. Considerable research is required to understand and overcome barriers to non-adherence with medication. Physicians must be aware of patient perception to illness and treatment and the need to play active role in patient education.

Acknowledgement: We acknowledge the support of Mr. Q. O Salaudeen for the secretarial services rendered in this work.

Conflicts of interest: The authors declare no conflicts of interest.

\section{References}

1. Sabaté E. Project WA to LTT, network GAI, diseases WHOD of M of N. Adherence to longterm therapies: evidence for action. http://www. who. int/ iris/ handle/ 10665/42682 (cited 25 Sep 2017).

2. Ferdinand KC, Senatore FF, Clayton-Jeter H, et al. Improving Medication Adherence in Cardiometabolic Disease. J Am Coll Cardiol 2017:69:437-51.8

3. Thinking outside the Pillbox: A System-wide Approach to Improving Patient Adherence for Chronic Disease." NEHI. 2009

4. Eaddy MT, Cook CL, O'Day K, Burch SP, Cantrell CR (2012). "How Patient Cost Sharing Trends Affect Adherence and Outcomes: A Literature Review".Pharmacy and Therapeutics.
$37(1): 45-55$

5. Kesselheim AS, Avorn J, Sarpatwari A (2016). "The High Cost of Prescription Drugs in the United States Origins and Prospects for Reform". JAMA. 316 (8): 858-871. do i : $10.1001 / \mathrm{j}$ a ma. 2016.11237 (https://doi.org/10.1001\%2Fjama.2016.11237).

6. Kaiser Family Foundation: Poll Finds Nearly Three Quarters of Americans Say Prescription Drug Costs Are Unreasonable, and Most Blame Drug Makers Rather Than Insurers for the Problem

7. Kennedy J, Morgan S. "Cost-related prescription non adherence in the United States and Canada: A system-level comparison using the 2007 international health policy survey in seven countries"Clinical Therapeutics. 31 (1): 213-219. doi:10.1016/j.clinthera.2009.01.006 (https://doi.org/10.1016\%2Fj.clinthera.2009.01 .006.)

8. "Enhancing Patient Adherence: Proceedings of the Pinnacle Roundtable Discussion ("http://www.pharmacist.com/AM/Template.cf $\mathrm{m}$ ? Section $=$ Home2\&TEMPLATE $=/ \mathrm{CM} /$ Conte ntDisplay.cfm\&CONTENTID=11174). APA Highlights Newsletter. October 2004.

9. Ngoh LN (2009). "Health literacy: a barrier to pharmacist-patient communication and medication adherence J" .Am Pharm Assoc (2003). 49 (5): e132-46; quiz e147-9. doi: $10.1331 /$ J A Ph A.2009.07075 (https://doi.org/10.1331\%2FJA PhA.2009.07075). PMID 19748861 (https://www.ncbi.nlm.nih.gov/pubmed/197488 $61)$

10. Elliott RA, Marriott JL (2009). "Standardised assessment of patients' capacity to manage medications: a systematic review of published $\begin{array}{llllllllllllllllllllll} & n & s & t & r & u & m & e & n & t & s & \end{array}$ (https://www.ncbi.nlm.nih.gov/pmc/articles/P MC2719637). BMC Geriatr. 9: 27. do i : 10 11186/1471-2318-9-27 (https://doi.org/10.1186\%2F1471-2318-9-27.) P M C $\quad 2719637$ (https://www.ncbi.nlm.nih.gov/pmc/articles/P M C 2719637 ). P M ID 19594913 (https://www.ncbi.nlm.nih.gov/pubmed/195949 13).

11. Berhe DF, Taxis K, Haaijer-Ruskamp FM, Mulugeta A, Mengistu YT, Burgerhof JG, Mol PG (2017). "Impact of adverse drug events and treatment satisfaction on patient adherence with antihypertensive medication - a study in ambulatory patients". Br J Clin Pharmacol. d o i : $10.1111 /$ b c p. 133312 (https://doi.org/10.1111\%2Fbcp.13312)PMID2 $\begin{array}{lllllll}8 & 4 & 2 & 9 & 5 & 3 & 3\end{array}$ (https://www.ncbi.nlm.nih.gov/pubmed/284295 33).

12. Nieuwlaat, Robby; Wilczynski, Nancy; Navarro, Tamara; Hobson, Nicholas; Jeffery, Rebecca; Keepanasseril, Arun; Agoritsas, Thomas; Mistry, 
Niraj; Iorio, Alfonso (2014-11-20). "Interventions for enhancing medication adherence". The Cochrane Database of Systematic Reviews (11): CD000011. doi:10.1002/14651858.CD000011.pub4(https:// doi.org/10.1002\%2F14651858.CD000011.pub4 . ) I S S N $1469-493 \mathrm{X}$ (https://www.worldcat.org/issn/1469-493X). P M I D

$\begin{array}{llllllll}2 & 5 & 4 & 1 & 2 & 4 & 0 & 2\end{array}$ (https://www.ncbi.nlm.nih.gov/pubmed/254124 02).

13. Sandra van Dulmen, Enmy Sluijs, Liset van Dijk, Deniscde Ridder, Rob Heardink and Jozican Bersing. Patient adherence to medical treatment: a review of reviews. BMC Health Science Research 2007, 7; 55: 1-13.
14. Hashmi SK, Afridi MB, Abbas K, Sajwani RA, Saleheen D, Frossard PM, Ishaq M, et al. Factors associated with adherence to anti-hypertensive treatment in Pakistan. Journal plosome 2007 (3) accessed online on 20/12/2016@ www.plosome.org

15. Hassan NB, Hasanah CI, Foong K, Naing I, Awang R. Identification of psychological factors of non-compliance in hypertensive patients. J Hum Hypertens 2006, 20; 23-29

16. Cramer JA, Benedict A, Muszbek N Keskinaslan A, Khan ZM. The significance of compliance and persistence in the treatment of diabetes, hypertension and dsylipidaemia. Int $\mathrm{J}$ Clin Pract 2008, 62 (1): 76-87. 
Table 1: Socio-demographic characteristic of the respondents

\begin{tabular}{lc}
\hline Variable & Frequency $(\%)$ \\
\hline Age (years) & $66(17.3)$ \\
$15-25$ & $67(17.6)$ \\
$26-35$ & $68(17.8)$ \\
$36-45$ & $72(18.9)$ \\
$46-55$ & $39(10.0)$ \\
$56-65$ & $69(18.3)$ \\
$\quad>65$ & $381(100)$ \\
Total & \\
Mean age 43.9 \pm 17.6 & \\
& \\
Sex of the respondents $(\mathrm{N}=381)$ & $98(25.9)$ \\
Female & $283(74.1)$ \\
Male & \\
Marital status $(\mathrm{N}=381)$ & $1(0.3)$ \\
Divorced / separated & $267(70.1)$ \\
Married & $101(26.5)$ \\
Single & $12(3.1)$ \\
Widowed & \\
Level of Education $(\mathrm{N}=381)$ & $100(26.4)$ \\
None & $73(19.0)$ \\
Primary & $89(23.2)$ \\
Pecondary secondary & $19(31.4)$ \\
\hline
\end{tabular}

Table 2: Treatment received by the patient before reporting at UITH

\begin{tabular}{ll}
\hline Variable & Frequency (\%) \\
\hline $\begin{array}{l}\text { Received treatment before } \\
\text { reporting at UITH }(\mathrm{N}=381)\end{array}$ & \\
Yes & $251(65.9)$ \\
No & $130(34.1)$ \\
& \\
Place of treatment $(\mathrm{N}=251)$ & $12(4.8)$ \\
Patient medicine store & $116(46.2)$ \\
Private clinic & $67(26.7)$ \\
Public hospital & $39(15.5)$ \\
Self medication & $17(6.8)$ \\
Traditional leader & \\
& \\
Type of treatment & \\
Received* $(\mathrm{N}=251)$ & $234(93.2)$ \\
Drugs & $7(2.8)$ \\
Operation & $19(7.6)$ \\
Traditional medicine & \\
\hline
\end{tabular}

Multiple response 
Table 3: Full adherence with prescription by age and educational level

\begin{tabular}{llll}
\hline Variable & \multicolumn{3}{c}{ Full adherence with prescription } \\
\hline Age (years) & Yes & No & Total \\
$15-25$ & $15(23.1)$ & $50(76.9)$ & 66 \\
$26-35$ & $21(31.8)$ & $45(68.2)$ & 67 \\
$36-45$ & $35(52.2)$ & $32(47.8)$ & 68 \\
$46-55$ & $36(49.3)$ & $35(50.7)$ & 72 \\
$56-65$ & $29(78.3)$ & $8(21.7)$ & 39 \\
$>65$ & $46(66.7)$ & $23(33.3)$ & 69 \\
& $\mathrm{X}^{2}=48.36, \mathrm{df}=5, \mathrm{p}<0.0001$ \\
Level of Education & Yes & No & Total \\
None & $69(69.0)$ & $31(31.0)$ & 100 \\
Primary & $52(72.2)$ & $20(27.8)$ & 73 \\
Secondary & $39(44.3)$ & $49(55.7)$ & 89 \\
Post secondary & $34(28.6)$ & $85(71.4)$ & 119 \\
\multicolumn{5}{c}{$\mathrm{X}^{2}=17.01, \mathrm{df}=3, \mathrm{p}=<0.0001$} \\
\hline
\end{tabular}

